\title{
Enteric Duplication Cyst in Infant: Case Report and Literature Review
}

\author{
Weber-Alvarez $\mathrm{P}^{* 1}$, Weber- Sánchez LA² and Mateos-López $\mathrm{AS}^{1}$ \\ ${ }^{1}$ General Physician, Hospital Angeles Lomas Huixquilucan, Mexico, Mexico \\ ${ }^{2}$ Department of General Surgery, Angeles Lomas Hospital, Mexico, Mexico
}

*Corresponding author: Weber Álvarez P, General Physician, Hospital Angeles Lomas Huixquilucan, Mexico, Mexico, Vialidad de la Barranca s/n C410, Valle de las Palmas, Huixquilucan PC-52763, Estado de México, México, Tel: 52469527, E-mail: pbl.weber@hotmail.com

Citation: Weber-Alvarez P, Weber- Sánchez LA, Mateos-López AS (2019) Enteric Duplication Cyst in Infant: Case Report and Literature Review. J Case Rep Stud 7(1): 102. doi: 10.15744/2348-9820.7.102

Received Date: December 15, 2018 Accepted Date: February 25, 2019 Published Date: February 27, 2019

\begin{abstract}
Congenital malformations can go unnoticed and have an impact on morbidity and mortality in early stages of life being a cause of infant death in some countries [1]. Malformations of the gastrointestinal tract occupy the second place among congenital abnormalities [2]. Along with them, the enteric duplication cyst is an infrequent anomaly difficult to diagnose specially for a non-specialist physician that is not use to attend this kind of pathologies or in hospitals where patients with this entities are infrequent. We present the case of a 5-month-old patient who underwent intestinal resection due to enteric duplication cyst.
\end{abstract}

Keywords: Enteric Duplication Cyst; Congenital Malformations; Gastrointestinal Malformation; Infant; Pediatric Surgery

\section{Introduction}

The enteric duplication cyst is an infrequent congenital anomaly that occurs in approximately 1 of every 5000 births. The etiology is uncertain and most cases are difficult to diagnose due to its vague symptoms depending on its location, size, presence of ectopic gastric tissue and the involvement of adjacent structures. It usually manifests as a medical emergency that requires surgery and therefore the diagnosis and treatment are performed usually during surgery.

\section{Case Report}

A 5-month-old male patient that was attended in a private institution, product of the third gestation obtained by caesarean section with weight at birth of $4200 \mathrm{Kg}$, APGAR of 9 and Silverman of 0, with no relevant past history in the previous pregnancies reported by the mother.

Upon questioning, the mother denied drug or alcohol consumption and there was no other relevant information concerning genetic malformations from both sides of the family. The parents mentioned that since birth, the infant presented abdominal pain mainly after nursing manifested by constant crying and cramping. Approximately 3 weeks prior to admission he started to present liquid stools with mucus and blood, occasional vomit and intolerance to oral feeding. Two different physicians change the hydration plan and gave him general measures. He increased the number of hemesis and presented fever $39^{\circ} \mathrm{C}$, so he was admitted to the hospital for diagnosis and treatment.

On physical examination the child was conscious, oriented with pallor and dried teguments and mucous membranes, normocephalic, auricular pavilions normally implanted, symmetrical eyes with normoreflectic-isochoric pupils, with no signs of cardiopulmonary pathology, abdomen distended, painful to palpation, soft and depressible with increased peristalsis and no signs of peritoneal irritation or visceromegaly, normal extremities. Vital signs at hospital on admission: Temp: $36.5^{\circ} \mathrm{C}$, Respiratory rate: $40 \mathrm{bpm}$, Pulse: $142 \mathrm{bpm}$. Relevant laboratory upon admission: $\mathrm{Hb} 9.7 \mathrm{~g} / \mathrm{dl}$, leucocytes $6.4 \mathrm{~K} / \mathrm{uL}$, bands $4 \%$, diffuse basophilia + , anisocytosis + , increased platelets count. He improved and tolerate better the oral feeding and his hydration status but at his third day of hospitalization he presented again irritable status, intolerance to the oral feeding, abdominal distension, evacuations decreased in consistency with subsequent constipation.

The abdominal X rays showed ileus with presence of hydro-aereal levels, dilation of intestinal loops and absence of distal air in the intestine (Figure 1). An orogastric tube was inserted, the abdominal ultrasound reported abundant fluid in intestinal loops and dilation of the colon. Intestinal transit with contrast media was performed to rule out occlusive process observing retention of the contrast media due to a narrowed segment in the intestinal lumen. 


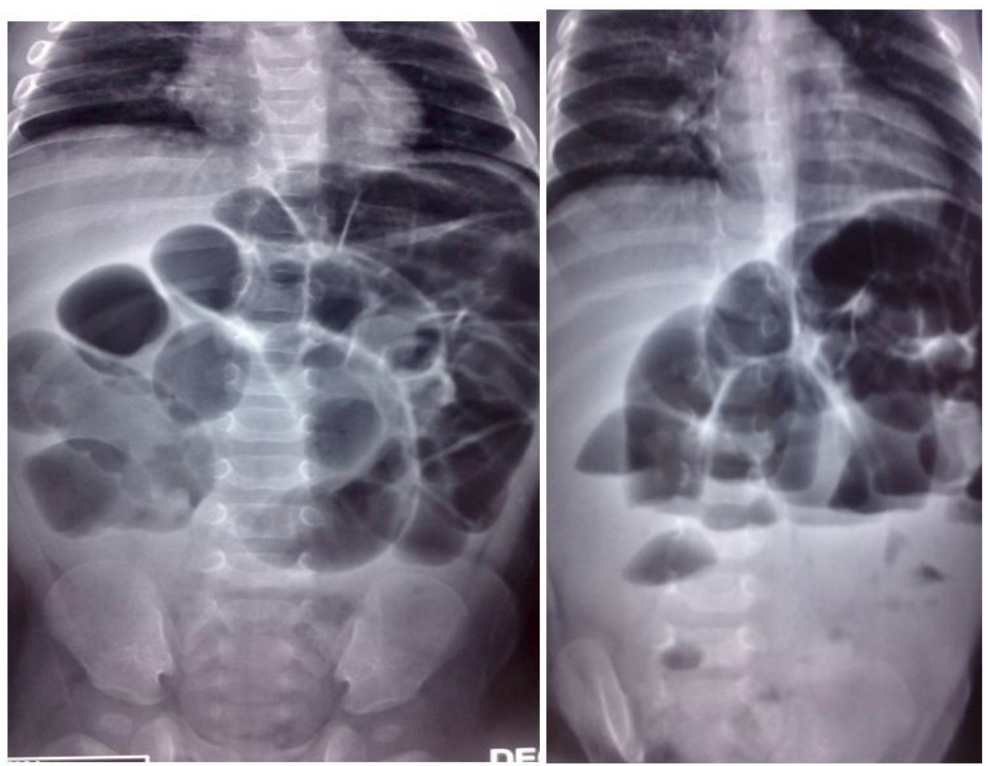

Figure 1: Abdominal plate in two positions with dilatation of intestinal loops, absence of distal air and hydro-aereo levels

Due to the vagueness of the data and the rapid deterioration of the patient and the acute presentation of the symptoms it was decided to perform exploratory laparotomy. The findings were complete intestinal malrotation, small bowel volvulus and a tumor in the distal ileum $5 \mathrm{~cm}$ far from the ileocecal valve that occluded 95\% of the intestinal lumen. Rearrangement of the small intestine and devolvulation was performed and the resection of the cyst was carried out along with $20 \mathrm{~cm}$ of distal ileum and cecum with appendix performing end-to-end ileocolic anastomosis (Figure 2,3 and 4). The pathology report was compatible with enteric

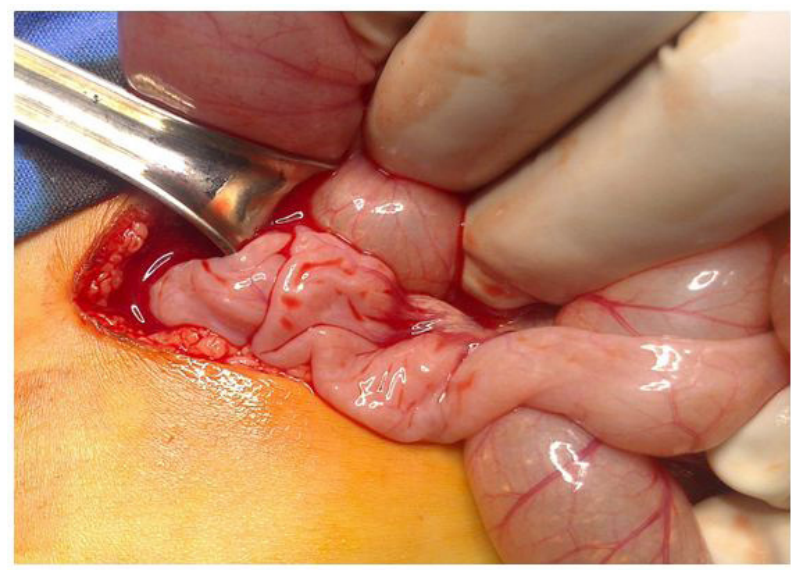

Figure 2: Intestinal malrotation
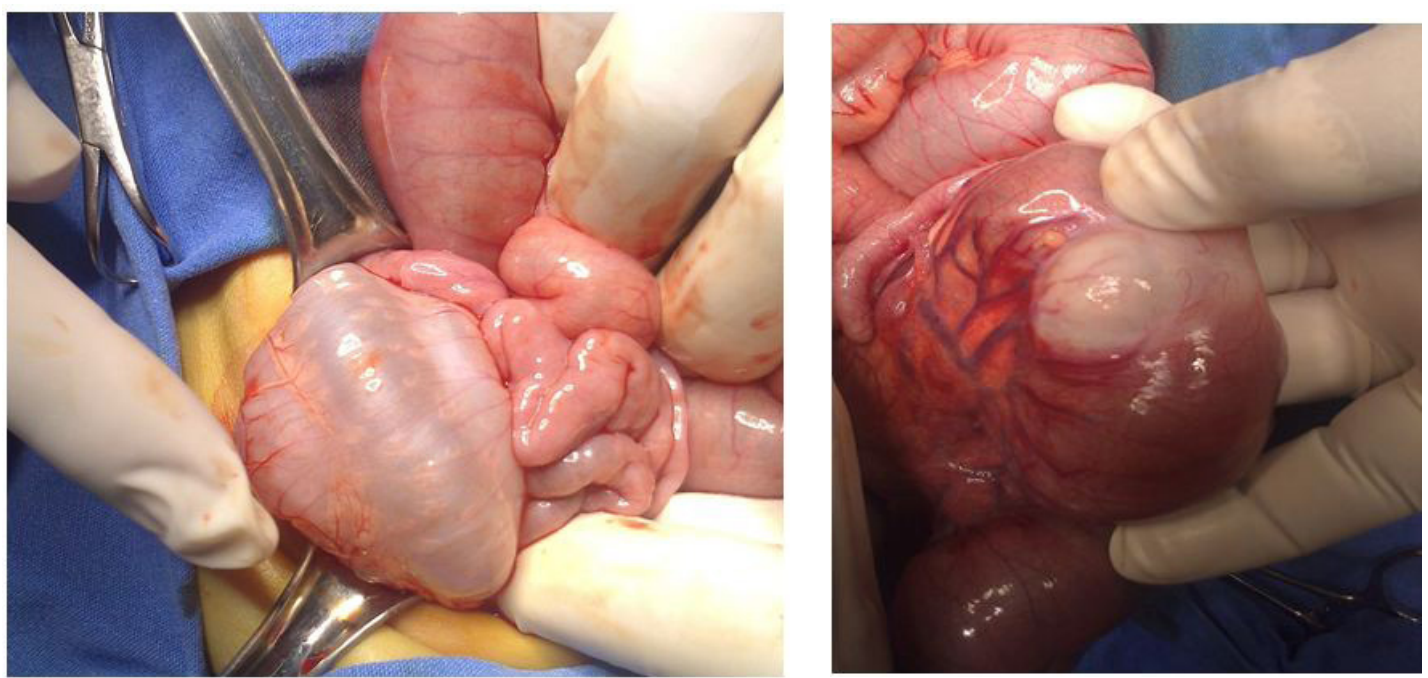

Figure 3: Enteric duplication cyst 
duplication with mucinous content. He was discharged 4 days after surgery, with normal oral feeding, asymptomatic, without abnormal signs on exploration. Currently the patient is stable with a satisfactory evolution.
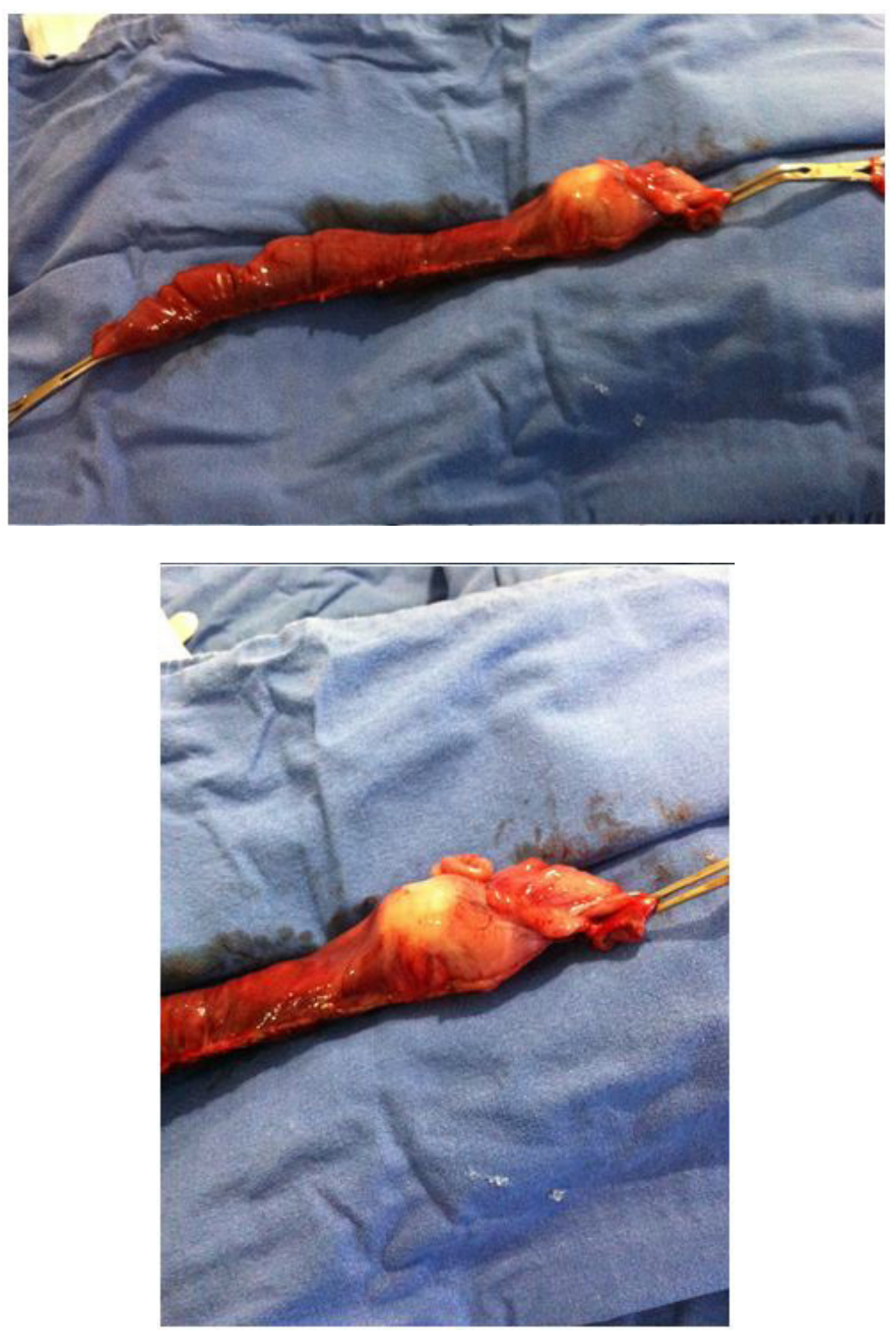

Figure 4: Surgical piece, enteric duplication cyst along with $20 \mathrm{~cm}$ of distal ileum and cecum with appendix

\section{Discussion}

Enteric duplication cyst is an infrequent congenital anomaly that mainly affects the small intestine related to the development of the gastrointestinal tract that affects 1 out of every 5000 newborns [3]. Usually is a surgical finding in both infants and adults in situations of digestive tract bleeding or acute abdomen. Because of this, it is convenient to have this entity in mind as one of the differential diagnoses. Many theories have been proposed about the origin of this disease; however, it continues to be unknown because of the inconsistencies in them. The "Diverticular theory" suggests that small transitory diverticula that are on the antimesenteric side of the intestinal wall of the embryo persists and turns into an enteric duplication cyst. Another theory is the lack of recanalization of the intestine after its solid stage during embryological development. There are others proposals that try to explain it but It doesn't do it in its entirety like "the notochord theory" that makes reference to abnormal diverticulization of the gastrointestinal endoderm during the development of the notochord in the fourth week of gestation or the mention of the involvement of environmental factors during the development of the fetus like hypoxia or trauma. The enteric duplication cyst could be located intramural or less frequently extramural. Could have ectopic gastric or pancreatic tissue with or without a common wall with adjacent organs. They are mainly located in the ileum (40\%), but they have been encountered in the esophagus, colon, jejunum, stomach, duodenum and rectum. Its presentation is usually cystic (90\%) but may be also tubular (10\%), single or multiple in up to $15 \%$ of the cases. Other malformations may be associated with it as spinal defects, intestinal malrotation as in this case, intestinal atresia and other abnormalities of the urinary tract [4-7].

Its relevance is due to the possible associated complications that can be life-threatening such as gastrointestinal bleeding (34\%) usually secondary to ulceration of the gastric mucosa, intestinal obstruction due to intussusception or intestinal perforation. 
In certain cases, a tendency to malignance of the ectopic tissue has been observed in adults; although the frequency of this is unknown it is advisable to remove it surgically since it is detected in childhood [8].

The diagnosis of this pathology is difficult because in most cases are asymptomatic and the most common associated symptoms are nonspecific. The physical examination also gives vague data du to its dependence on the size, presence of the ectopic gastric tissue and the involvement of adjacent structures. The differentiation with other abdominal cysts (ovary, mesentery or common bile duct) should be carried out in addition to other etiologies that could produce dilation of bowel loops or urological problems.

The evolution in pre and postnatal diagnostic studies allows an early and more frequent diagnosis. CT scan is the most useful but MRI can be also helpful, plain X rays are not specific as they only may reveal dilation of bowel loops. Technetium scintigraphy can also be helpful specially if there is ectopic gastric mucosa, but it does not distinguish it from Meckel's diverticulum. Ultrasound guides the diagnosis if a "double wall" image is identified, especially in the prenatal period. Definitive diagnosis is made with the patho-anatomical study of the surgical piece where up to $30 \%$ of the cases can be found ectopic gastric mucose [9].

The treatment is surgical consisting of total or partial removal of the malformation with end-to-end anastomosis; however, there is no unique technique to do this due to the variability of the morphology and extension of the duplications. Ladd's procedure is performed in those patients with intestinal malrotation consisting in mobilization of the duodenum and the right colon, section of the Ladd's bands, section of possible adhesions near the superior mesenteric vessels and appendectomy. There is general consensus for patients with chronic presentation to undergo an elective Ladd procedure and for those with acute presentation of volvulus to require emergent laparotomy [10]. In the case of our patient due to the vage and acute symptomatology a laparoscopy was performed with a Ladd's modificated procedure. Recently, diagnostic and therapeutic laparoscopy has been used in the management of surgical pathology in children from birth to adolescence [11-13].

\section{Conclusion}

The enteric duplication cysts are a rare entity of the child population, usually difficult to diagnose and with potential severe complications, so it should be kept in mind in acute abdomen situations in infants, as it was this case.

\section{References}

1. Valdés SY, Trinchet SRM, Velázquez RG, Sánchez RE, Reyes FJ (2013) Embryopathology of duodenal obstruction Application in the evaluation of results in neonatal surgery (Embriopatología de la obstrucción duodenal. Aplicación en la evaluación de los resultados en cirugía neonatal,). Rev Cub Gen.7: 23-6.

2. López PC (1977) Dia to the records of congenital malformations. (Dcia a los registros de malformaciones congénitas). Rev Cub Adm Salud 3:183-93.

3. Kim EP, McClenathan JH (2001) Unusual duplication of appendix and cecum: extension of the Cave-Wallbridge classification. J Pediatr Surg 36: 18-19.

4. Seguel FR, Alvarez MBQ, Ollero JCF, Rollan VV (2002) Independent intestinal duplication (Duplicación intestinal independiente). Cir Pediatr 15:127-9.

5. Soares-Oliveira M, Castañón M, Carvalho JL, Ribo JM, Bello P, et al. (2002) Intestinal duplications Analysis of 18 cases (Duplicaciones intestinales: Análisis de 18 casos). Ann Pediatr 56: 430-3.

6. Pintér AB, Shubert W, Szemlédy F, Göbel P, Schäfer J, et al. (1992) Alimentary tract duplications in infants and children. Eur J Pediatr Surg 2:8-12.

7. Letelier MA, Barría MC, Beltran SMA, Moreno CHC (2009) Intestinal duplication: Diagnosis and treatment of an unusual condition (Duplicación intestinal: Diagnóstico y tratamiento de una condición inusual). Rev Chilena de Cirugía 61: 171-5.

8. Keckler S, Holcombm G (2010) Alimentary Tract Duplications. Ashcraft's Pediatri Surg ( $5^{\text {th }}$ edn) $517-25$.

9. O 'Neil J. Rowe MI, Grosfeld J, Fonkalsrud E (1998) Pediatric surgery ( $5^{\text {th }}$ edn). Naschville 1257-67.

10. Christine Wang, Tyrone Rogers, Katherine Su, Eugene P Ceppa (2017) Laparoscopic Ladd's procedure for intestinal malrotation in the adult patient without volvulus: Surgical technique (Laparoscopic Ladd's procedure for intestinal malrotation in the adult patient without volvulus: Surgical technique). J Gastroenterol Dig Dis 2: 29-32.

11. Guérin F, Podevin G, Petit T, Lopez M (2012) Outcome of alimentary tract duplications operated by minimally invasive surgery: a retrospective multicenter study by the GECI (Groupe d'Etude en Coeliochirurgie Infantile). Surg Endosc 26: 2848-55.

12. Polliotto SD, Luciani JL, Allal H, Galifer RB (1996) 527 cases of laparoscopic and thoracoscopic surgery in pediatrics. (527 casos de Cirugía laparo y toracoscopica en pediatría). Revista de Cirugía infantile 6: 116-22.

13. Kalfa N, Allal H, Raux O, Lardy H, Varlet F (2007) Multicentric assessment of the safety of neonatal videosurgery. Surg Endosc 21: 303-8. 


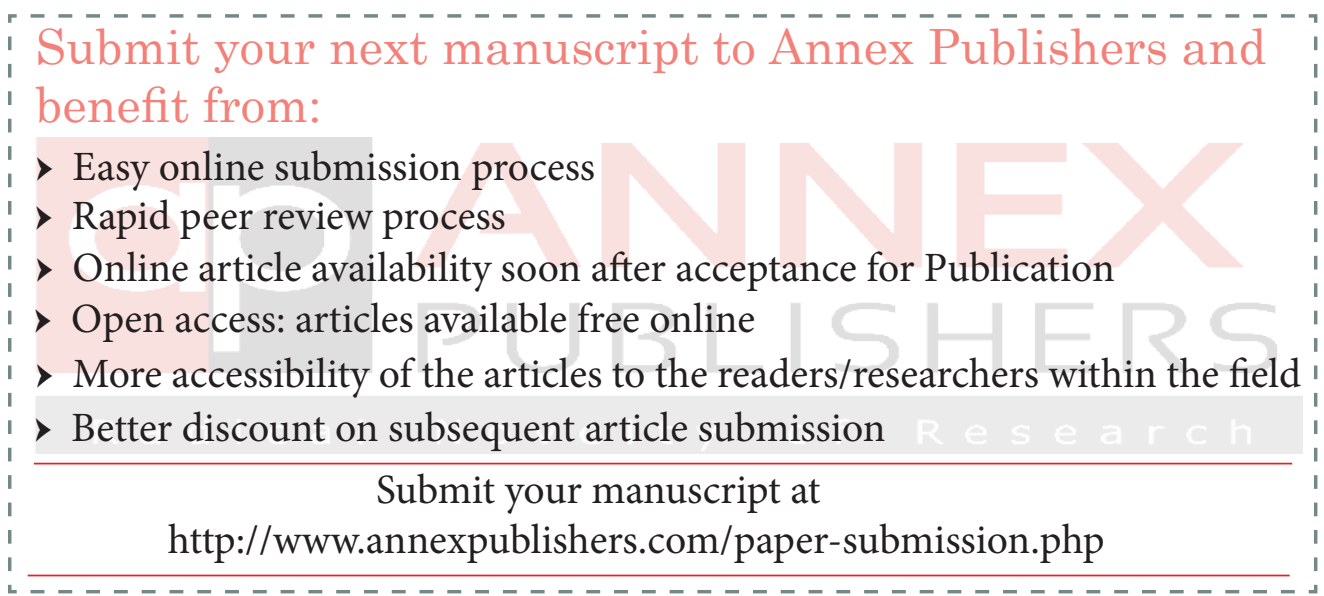

